\title{
MIL L. MIKHAIL AND TSAGI
}

On November 22, 2009, 100 years had passed since the birth of the outstanding Russian scientist and helicopter designer M. L. Mil. During the period 1947 to 1970, first as design manager and then chief designer, Mikhail L. Mil was at the forefront in the engineering of outstanding helicopters, civil and military helicopters of the mark "Mi". Developed by the experimental design office (EDO), these helicopters are known all over the world and are in great demand on the domestic and foreign market. More than $90 \%$ of the helicopters currently produced in Russia are the "Mi" helicopters, having the basic design laid out by M. L. Mil. In Soviet times the "Mi" helicopters exceeded the helicopters of other countries by total capacity.

M. L. Mil was closely related to TsAGI throughout his extraordinarily creative career in the pursuit of multifaceted research interests.

\section{GYROCOPTERS}

Mikhail Mil, being a student of the Faculty of Aerodynamics of Novocherkassk Polytechnic Institute, was absorbed by the theory and practice of gyrocopter creation and studied with interest all the available works on the issue. In 1929 he wrote a letter to Nikolay I. Kamov, a known designer of gyrocopters, in which he demonstrated deep knowledge in this area, requesting a position which would allow him to work under his supervision during the student holidays. His request was granted. That summer he worked as an assistant engineer on the flight tests of the gyrocopter KASKR-1 of Kamov and Skrzhinsky design. In 1930 M. Mil, although he was currently in Taganrog, requested that he perform his pregraduation practical work at the Department of Experimental Aerodynamics of TsAGI, and in 1931 he began working in this department as a full staffer. His assignment was to perform calculations and experimental investigations with regard to gyrocopter aerodynamics. In 1933 the gyrocopter section in the Department of Experimental Aerodynamics was reorganized under the Department of Special Design of TsAGI, which was engaged in the design of helicopters and gyrocopters. Mikhail Mil was appointed head of the gyrocopter aerodynamic calculation team in the Department of Special Design.

Throughout 1940 a number of TsAGI gyrocopters were designed and constructed at the Department of Special Design. All these works were performed by Mil's team. But Mil was not restricted to the implementation of aerodynamic research, computational investigations, and wind tunnel tests; he literally "was in on" all the questions related to the development, flight test support, design, and construction. Thus, while developing the A-6, "ground resonance" type self-oscillations were successfully eliminated with 
the active participation of Mil. These works successfully combined the talents of two outstanding scientists-V. A. Kuznetsov and M. L. Mil.

In March 1940 M. L. Mil was employed in factory no. 290 and became the deputy of the design manager N. I. Kamov. He participated in the production and organization of the A-7 gyrocopters used in the battles of Yelnya in August-September 1941, for which he was awarded the Order of Red Star and other medals.

\section{AIRCRAFTS}

In May 1943 M. L. Mil returned to TsAGI, where neither gyrocopter nor helicopter research and design existed at that time. Organized at the recommendation of I. V. Ostoslavskiy in laboratory no. 1 was the Aircraft Stability and Control Group. Mil had begun to study these issues in 1940. The vast experience he gained during his works on gyrocopters proved useful to him. In his role as chief of the Aircraft Stability and Control Group in laboratory no. 1 of TsAGI, Mil focused not only on control simplification and improvement of pilot comfort, but he also directed his efforts toward aircraft combat applications - increasing the accuracy of aircraft shooting and bombing-which was, of course, of special interest in wartime.

Theoretical analysis of the perturbed motion of the aircraft upon entrance to gusts and the definition of loads on the controls were carried out. The requirements to the loads on the control stick were formulated for the weakly stable aircraft in order "to connect" the pilot with the vehicle. Practical proposals to install special shock dampers on the control stick or springs on the control crank in the longitudinal channel were confirmed experimentally in the T-101 wind tunnel and on real aircrafts in flight tests.

During this period Mil and his colleagues studied the influence of friction in the control circuit on the flight performances of aircrafts in detail. They established that a significant friction in the longitudinal or transverse control channel was perceived by the pilot as a reduction of the longitudinal or, respectively, lateral aircraft stability and resulted in a decrease of the controllability estimation of the maneuverable aircrafts. Recommendations were made regarding acceptable friction force values in the control systems of different aircrafts, as well as acceptable relations between the value of friction forces and the gradient of load growth by the stick deflection, providing regular aircraft controllability. Standardized instructions on friction control in the aircraft control system were developed.

All these investigations were aimed at improving the lift-to-drag ratio of the serial military vehicles I-16, DB-3 (Il-4), SK-1, SK-2, OKO-6 bis, LAGG-3, Pe-2, La-5, and Il-2, which was extremely important during the war. During these years Mil worked closely with aircraft designers S. V. Ilyushin, S. A. Lavochkin, and A. I. Mikoyan. After the war M. L. Mil, as a member of staff, was sent to Germany from where they brought the T-107 wind tunnel which operates at TsAGI at present. In October 1943 M. L. Mil defended his $\mathrm{PhD}$ thesis on the issues surrounding aircraft stability and controllability. For his work in this area he was awarded the Order of the Patriotic War of $2^{\text {nd }}$ Class. 


\section{HELICOPTERS}

After World War II Mil's research focused on rotary wing aircrafts. Based on his works on rotor aerodynamics, in October 1945 he successfully defended his $\mathrm{PhD}$ thesis and became the head of the department in laboratory no. 1 of TsAGI, where he assembled a close-knit, like-minded group and aimed the work of his department toward helicopters. Together with V. I. Yaroshenko, in a short time he developed an original method of helicopter aerodynamic calculation based on direct consideration of the vehicle polar. This method was necessary for Mil for practical purposes. On his own initiative he began to develop the experimental three-seat helicopter EG-1 at TsAGI, which was designed in the classical single-rotor scheme with the tail rotor, an M-13 engine, and with an original device performing automatic increase of flight stability. April 9, 1946 this helicopter project was submitted to the Ministry of Aircraft Production Commission, which supported the project but with a number of recommendations.

Based on the decision of the Ministry of Aircraft Production Commission, Mil proposed to build a full-scale helicopter plant for the tests in the T-101 wind tunnel. In accordance with Mil's idea, this plant was created for single-rotor helicopter production, but without devices counteracting the reactive moment from the rotor, gear, and other units. This significantly reduced the time for this plant "conversion" to helicopters.

The laboratory for solving scientific problems related to helicopter construction and aircraft spin was created in 1947 based on the TsAGI T-105 vertical wind tunnel. M. L. Mil was appointed head of the laboratory and its helicopter sector. Of course, Mil's experience working with rotary-wing and aircraft equipment contributed to this decision of joining seemingly different directions. Employees of the helicopter sector (more than 20 people) formed the basis for the future EDO of Mil. Almost none of them had previous experience in the design and construction of rotary-wing equipment. Therefore, Mil's knowledge in the area of aerodynamics, design, and construction of both a vehicle as a whole and its individual units, as well as his experience in flight development of rotarywing equipment, were overwhelmingly important. The cohesion and purposefulness of like-minded fellows contributed to the fact that in a very short time the full-scale helicopter was built and tested in the T-101 wind tunnel. In the autumn of 1947 the full-scale model of the three-seat helicopter EG-1, created in Mil's laboratory, was approved by the government commission.

December 12, 1947 the Council of Ministers of the USSR adopted a special resolution to create a communications helicopter for the Armed Forces of the USSR. According to this resolution, the design teams of A. S. Yakovlev, I. P. Bratukhin, and M. L. Mil were ordered to create prototypes of the new helicopters; thus, development of the communications helicopter was actually a competition. The resolution also obligated the deputy minister of aircraft production to organize at TsAGI the Experimental Design Office on Helicopters and to approve the design manager of this EDO, M. L. Mil. December 12 is the official date of creation of the EDO named after M. L. Mil. By the end 
of July 1948 the EDO was located in the building of the T-105 vertical wind tunnel at TsAGI. It was later relocated in Tushino and after that to 3 Rybinskaya str. at Moscow. But Mil worked at TsAGI part-time until the mid-1950s.

Created under the leadership of M. L. Mil before 1970 were the helicopters Mi-1, Mi-4, Mi-6, Mi-10, V-7 (with the jet drive), Mi-2, Mi-8, Mi-14 (amphibian), V-12, Mi-20 (project), and Mi-24. The research and development for all these helicopters to a greater or lesser degree was carried out at TsAGI.

It should be noted that the close cooperation of TsAGI with EDO was sometimes accompanied by serious discussions on questions of principle. Discussions with regard to the transverse scheme helicopter V-12 were especially hot: TsAGI was in principle against this scheme. But Mil's leadership guided the discussion, ultimately ensuring that the correct decision was made-to proceed with plans to build the vehicle. Being the head of the EDO, M. L. Mil always promoted and advanced the ideas in which he believed. On important issues he was known to lobby the government directly, even making his case personally to Khrushchev. From this point of view, M. L. Mil was not only a designer, but by present standards, an excellent manager.

M. L. Mil's activity at TsAGI since 1943 and after in the EDO was of great importance to the formation and development of Russian science and helicopter engineering schools.

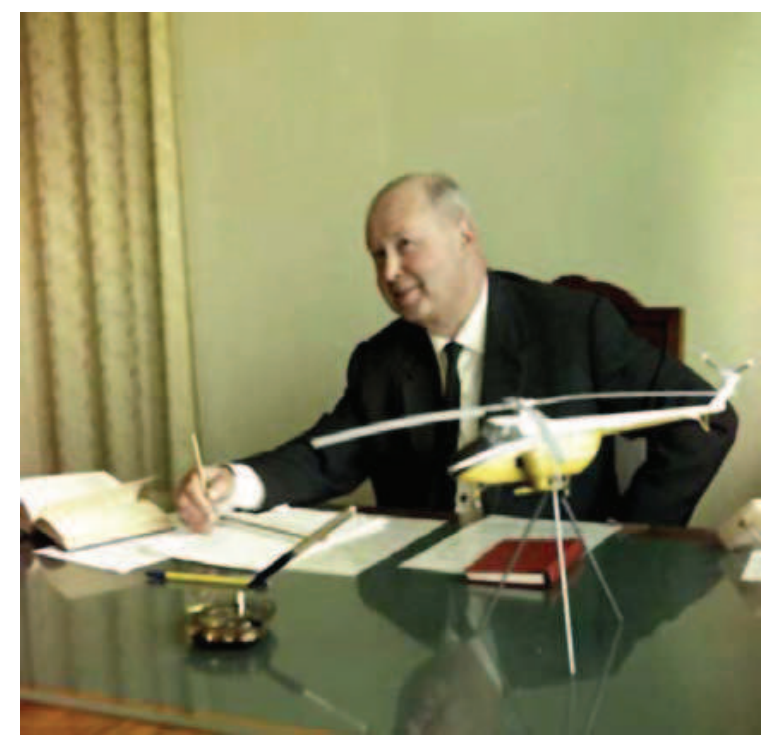

"We have a great future, but we remember our relationship. Conceptually we are the followers of the great Russian school of aerodynamics, founded by Nikolai E. Zhukovsky, and of his disciples B. N. Yuriev and A. M. Cheremukhin. Inherently we came out of TsAGI, and therefore we are related to the science by blood ties..." (From the speech of M. L. Mil on the meeting devoted to the $15^{\text {th }}$ Anniversary of EDO.) 